\title{
Why Students Fail in History: A Minor Case Study in Malaysia and Solutions from Cognitive Psychology Perspective
}

\author{
Chee-Huay Chong \\ Faculty of Education, Universiti Teknologi Malaysia, 81310 Skudai, Johor, Malaysia \\ Email: crayonace@gmail.com
}

Kee-Jiar Yeo

Associate Professor, Faculty of Education, Universiti Teknologi Malaysia, 81310 Skudai, Johor, Malaysia

Email:kjyeo@utm.my

\section{Doi:10.5901/mjss.2016.v7n1p517}

\section{Abstract}

The importance of History in fostering effective citizenship is beyond question. Hard as students study History, some of them fail to achieve higher grades. Hence, History seems to create problems for many students. The current research is a minor case study aimed to examine the causal factors that induce to a poor achievement in History and provide study strategies accordingly to enhance students' achievement in the subject. The sample consisted of 2 participants from government secondary schools. The participants obtained poor grades in History. After interviewing the participants, the findings shows that: (i) pay less attention, (ii) poor study skills, and (iii) poor time management were the causal factors of poor performance in History. Therefore, five learning strategies - (i) paying attention, (ii) rehearsal (revision), (iii) elaboration-based learning techniques, (iv) mnemonics, and (v) comprehensive approach - are recommended as remedies for the low History achievement. The applications of the above-mentioned remedies are discussed across a variety of History topics.

Keywords: History, study skills, cognitive psychology, memory, Malaysia

\section{Introduction}

In Malaysia's education system, History is a core subject in secondary schools. History is viewed as an important tool to cultivate loyal patriotism among Malaysians with demography represented by diversities in ethnic groups, culture, religions, and linguistic affiliation. Thus, History can be viewed as a vital apparatus to foster national integration and unity (Mohamad Johdi Salleh et al., 2013). Not restricted to Malaysia, History demonstrates its great power in shaping citizenship worldwide. According to Jenness (1990), in the early twentieth century, History functioned as a tool for socializing the huge number of immigrants in the United States (as cited in Brophy \& VanSledright, 1997).

Starting from the year 2013, History became one of the compulsory pass subjects in order to obtain the Malaysian Certificate of Education, a national examination which is taken by secondary five (or equivalent to eleventh grade) students. Obviously, a good understanding of History is essential, not only because it shapes patriotism, it is also an academic criterion to be satisfied by Malaysian students.

Ironically, History could be one subject that creates painful headaches for many students. The importance of learning History has always been overlooked by the young generation. According to Azwan Ahmad et al. (2005), History is regarded as a boring and tedious subject in Malaysia. Moreover, Malaysians tend to view that learning History has no commercial value, Azwan Ahmad et al. (2005) further added. Thus, it can be foreseen that these preconceived ideas frustrate and demotivate students in the route of learning History.

One of the contributing factors to the low achievement in History may be due to the conventional way students study the subject. A student might just simply memorize everything from textbooks in a rough-and-tumble way. As a consequence, History becomes an incomprehensive and monotonous subject. Eventually, History appears to be very difficult to learn.

Instead of merely a dull and dry process of reading and memorizing historical events, learning History definitely is a cognitive process. Thus, current research attempts to seek the causal factors that lead to poor performance in History and proposes learning strategies to remedy the issue. 


\section{Literature Review}

\subsection{Learning History}

History, as argued by Jenkins (2002), is a subject which could be viewed as a body of knowledge, requires learners undertake both surface and deep learning approaches in order to perform well in the subject. At first, learners are required to undertake surface learning in memorizing historical facts (e.g. lists of dates). Then, developing a depth of understanding of the subject is acquired after undertaking deep learning approach, for examples, analysis, interpreting, and understanding facts on a timeline. In other words, learning History is not an art of learning by rote, but making sense of the memorized historical facts.

Recent research reveals that the presentation of history topics in textbooks plays a part in facilitating and triggering interest in learning the subject. Gültekin and Berk (2011) reported that some historical themes, for instances, regional history, history of World and European, and Turkish and World history after 1938, were found to be difficult among 131 Grade 12 students in Turkey. The researchers argued that the arrangement of those difficult historical themes in textbooks did not follow students' interest and the themes were presented in a manner void of visual expression.

Besides, teachers also serve a primary determinant of student success in learning History. Reisman and Wineburg (2008) suggested teachers to encourage students think contextually in History class. The researchers furthered added that contextualized teaching means the act of organizing events in a well-constructed context which allowing teachers to illustrate how a historical event evolves for students. Thus, it will provide a dynamic picture on the interconnection of historical events. To do so, teachers could: (i) giving background information, (ii) using guiding questions, and (iii) creating contextualized thinking explicitly.

For another, Beyer (2008) stressed the importance of applying thinking skills in learning History. He claimed that teachers should implement teaching skills that encourage students' thinking skills in teaching History and Social Science as such complex thinking skills are essential to academic success. Lastly, thinking skills would not only enhance students' thinking quality, but also enable students to achieve higher grades, the researcher pointed out. This research provides an implication that students will obtain good grades in History, if they perform a deep level of processing to encode information.

\subsection{Memory System}

In the context of learning History, students are required to remember and recall successions of facts, including dates, people, places and major events. Then, to have a deep understanding of the subject, students need to establish links among the remembered facts. Such memorizing and recalling mechanisms are parts of human memory (Huitt, 2003).

To study human memory, as stated by Klatzky (1984), most current research studies are conducted based on information-processing theory (as cited in Wood et al., 2011). As explained by Wood et al. (2011), information-processing approach involves three stages: Encoding, Storage, and Retrieval. The first stage, encoding, is a process that converts information into memory. Then, storage keeps and maintains the information in memory. The last stage, retrieving information is about recalling the stored information. These three processes must be undertaken, if we want to remember something.

In respect of the human memory in information storage and retrieval, Atkinson and Shiffrin (1968) viewed that the memory systems are formed by three stages involve: Sensory Memory (or Sensory Register), Short-term Memory (or Short-term Store, Working Memory), and Long-term Memory (or Long-term Store). Sensory memory refers to registration of stimulus from the environment by human sensory organs. Meanwhile, short-term memory holds information which is assumed to be completely decayed for a certain short period of time. The information is stored in short-term memory, however, takes significantly longer time to disappear as compared to sensory memory. In contrast to sensory memory and short-term memory, the final stage of memory system, long-term memory stores information over a long period of time. Thus, the information stored in long-term memory is relatively permanent.

As explained by Goldstein (2011), long-term memory could be branched by dichotomy into two main divisions, namely explicit memory (consists of episodic memory and semantic memory) and implicit memory (consists of priming, procedural memory, and classical conditioning). In the domain of explicit memory, as claimed by Tulving (1972), episodic memory is a record of temporal details (e.g., dates and times) of certain events; while semantic memory is a record of general knowledge (e.g., meanings of words and concepts). For the another subsystem of long-term memory, based on Goldstein (2011), priming refers to the changes of a response due to the prior similar stimulus (e.g., we are easier to remember familiar words than the unfamiliar ones); in the other hand, procedural memory is responsible in doing things 
(e.g., typing notes); and classical conditioning involves pairing a new stimulus with another stimulus and causes the former stimulus acquiring new properties (e.g., a car driver who is a survivor of a road accident involving a red car might feel anxious whenever seeing a red car).

To facilitate better understanding of short-term memory and long-term memory, the discussion now focuses on the capacity between the two terms. Short-term memory has limited capacity to hold information. For example, the capacity of short-term memory to recall a variety of test materials is about 7 items (Miller, 1956). According to Carter and Seifert (2013), the capacity of long-term memory, however, is unlimited and it can store information for a long time. Nevertheless, exciting studies show that the performance of short-term memory could be enhanced through strategic training (Butterfield et al., 1973; Carretti et al., 2007). Besides, short-term memory could be converted into long-term memory through memory strategies which include: practicing memory rehearsal, relating novel information with something that could make it more memorable, and paying attention (Goldstein, 2011).

\subsection{Memory Enhancement}

Recent research has proposed several memory enhancement techniques to improve mental performance.

Based on existing research, Schwartz et. al. (2011) suggested four memory enhancement techniques to learners: (i) process information actively, (ii) practice retrieval, (iii) adopt distributed practices, and use metacognition. The researchers pointed out that these techniques could increase overall learning outcomes. That is, by practicing the abovementioned techniques, learners can learn more in a given study time. Therefore, the researchers concluded that memory enhancement techniques provide beneficial effects to the learners in educational settings, as well as the learners in every industry, from children to old folks.

Besides, Tuckman (2003) has conducted a research to study the effects of learning and motivation strategies on students' academic performance. The researcher found that students who completed the training course earned higher GPAs in contrast to the matched students. Thus, the researcher further suggested that teachers could run a learning and motivation strategies workshop to at-risk students.

Memory improvement skills also have positive impacts on elderly persons. The research findings by Cavallini et al. (2003) revealed that memory training improves cognitive performance of elderly people and they benefit from memory training as much as adult and young elderly. Additionally, Mohs et al. (1998) pointed out that older adults (ages 60-90) who completed a training course in memory enhancement showed better memory functioning, compared to control groups.

In addition, memory training appears to be effective in facilitating memory abilities for people with disabilities. Research aimed at understanding the effects of rehearsal training on children with fetal alcohol spectrum disorder has been conducted by Loomes et al. (2008). The research findings showed that the trained children surpassed the control group, for example, the former had better memory for numbers. Now, we shift to the aged. After conducting research consisting of elderly people with mild cognitive impairment, Rapp et al. (2002) found that individuals who received a multicomponent memory enhancement training which included memory skills training had better memory appraisals than the untrained individuals.

These studies yield a fairly consistent conclusion that memory could be trained and improved, even for mentally retarded individuals.

\section{Method}

\subsection{Research Design}

This paper is a minor case study. According to Yin (2009), case study is very suitable to investigate a real-life phenomenon in depth and answer "why" research questions. The main objective of current research is to understand why there are some students always get low grades in History. By knowing the causal factors, learning strategies will be proposed accordingly to improve learning outcomes.

\subsection{Participants}

Purposive sampling was applied in sample selection. According to Teddlie and Yu (2007), purposive sampling means choosing subjects based on certain criteria associated with answering research questions. Bernard (2002) further added that there is no cap on the number of sample in purposive sampling provided that information is gathered (as cited in 
Tongco, 2007). Hence, two subjects were selected purposively. Both of the participants were Grade 8 and Grade 9 students from public secondary schools in Malaysia. The participants were chosen as they had low achievement in History.

\subsection{Data Collection}

The needed information was collected by using one-to-one semi-structured interview. Semi-structured interview, as viewed by Fylan (2005), is very suitable to answer 'why' questions because it enables the researcher to ask what participants have experienced and what participants think about the topic of interest. Hence, the researcher could explore deeply to what he or she is interested in. During the interview sessions, participants were exposed to open-ended questions. Open-ended questions allow the interviewees to speak out their personal experience unconstrained (Creswell, 2012). Through semi-structured interview sessions with open-ended questions, we obtained rich information to study the crucial factors that lead to poor achievement in History.

\section{Findings}

\subsection{The Causal Factors of Low Achievement in History}

For the semi-structured interviews, three causal factors have been identified: pay less attention, poor study skills, and poor time management.

\subsubsection{Pay Less Attention}

Participants were asked about what they did during History class. The participants did not listen carefully and pay little attention to the class. Participant A answered the questions by saying, "I used to talk with friends during the class, especially when the teacher asked me to copy down notes from the textbook." Participant A tuned in gossips of various forms of topics, particularly but not exclusively online games. Meanwhile, Participant B reported that he used to do textbook doodles.

\subsubsection{Poor Study Skills}

The participants were also exposed to questions regarding learning strategies, for examples, "Do you have any revisions before the exam?", "What are your learning strategies to study History?", "Do you make your own notes?", and so forth. The findings revealed that the participants did not practice good study habits. They tended to learn by rote. Typical responses include:

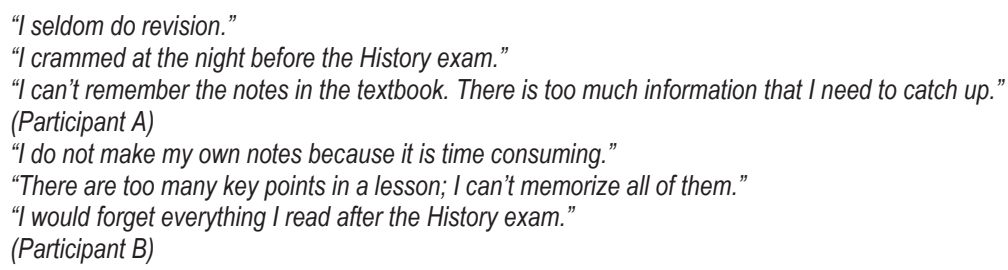

Indeed, rote learning has many limitations. Poor learning habits demotivated the participants and made them feel powerless in learning History. Moreover, such habits lead to a lack of confidence in learning. Participant B spoke of his negative thinking, "I know I will fail in the exam, so I don't want to waste my time with revision."

\subsubsection{Poor Time Management}

The participants did not allocate sufficient time to study History. This statement is derived from the participants' quotes, such as "I spend my time in playing electronic games and watching comics before sleep." (Participant A), "Sometimes, I watch movies until late at night." (Participant B), and "I did not study History on a regular basis; instead, I used to pull an all-nighter for the exam." (Participant B). Admittedly, allocating sufficient time to study History is a critical element of better 
performance in the subject. Inability to make effective use of time has a detrimental effect on achievement in History.

\subsection{Study Skills for History}

After reviewing the causal factors that lead to poor achievement in History, the current researchers proposed five remedies to the dilemma. Each remedy comes with its applications.

\subsubsection{Paying Attention}

Some inattentive behaviors were reported by the participants - gossiping and doodling. They branched off their mind into irrelevancies. They split their concentration.

Attention is a key principle of success in learning. According to Ward (2004), when we pay attention to several stimuli, we tend to end up with worse performance as compared to when we carry out them separately. For example, divided attention declines accuracy of remembering (Dudukovic et al., 2009). In other words, when we divide our attention, learning becomes ineffective. On the contrary, by giving more attention to an event, we are more likely to learn it (Gerrig, 2013). Without paying enough attention, we could not encode new information effectively, as stressed by Smith and Kosslyn (2007).

Paying attention is the very first step to learn new things. To enhance learning outcomes, students should concentrate on their History lessons and listen to their teachers; moreover students also need to avoid being sidetracked by irrelevant activities, for examples, gossiping with others, doodling, and the likes.

In addition, a good learning environment, which frees from distractions, makes learning more productive. Recent studies show that studying in a noisy environment does not give learning a favor. Noise can harm accuracy (Hygge \& Knez, 2001), and cause detrimental effects on long-term memory and reading (Hygge at al., 2002). Besides, students should keep themselves away from distraction sources in the learning process. Turn off phone ringer and move away electronic gadgets, for examples. Otherwise, student would end up busy texting and checking social networking sites.

Indeed, paying attention is a part of learning History. Students who fail to pay attention are at the cost of lower grades in History.

\subsubsection{Rehearsal (Revision)}

Time, undoubted, is a scarce resource. The participants in this study seemed perceptually busy with their daily tasks. The findings, however, revealed that they faced a dilemma in allocating a large portion of time playing electronic games. According to the total time hypothesis, the amount learnt is directly proportionally to the total devoted time (Sternberg, 2009). Thus, they should set a side sufficient time slots for their learning, for example, revision.

Revision can be viewed as parallel to rehearsal in cognitive perspective. Rehearsal means repeating information again and again (Goldstein, 2011). As explained by Lieberman (2012), if one repeats a word to be remembered before it decays in short-term memory, the word would return to full strength and then has the likelihood to be converted into longterm memory. Rehearsal yields numerous advantages. According to Weinstein and Mayer (1986), rehearsal limits students' attention to important parts of the material and puts them into working memory for later use. In the words of Tony Robbins (a motivational speaker), "Repetition is the mother of all skill" may be a truism in mastering History.

Rehearsal techniques, according to Weinstein and Mayer (1986), require students learning actively in speaking, writing or pointing to the academic materials, for instances, reading aloud repeatedly, copying texts, making notes, and underlining the key points. A research conducted by Rickards and August (1975) showed that students who underlined sentences in a passage performed better in recalling information than those did not do so. Apart from underlining sentences, it is also evident that highlighting text enhances learners' retention of the highlighted materials (Fowler \& Barker, 1974). Making notes, another rehearsal technique, is a process that requires an individual to understand and select importation information from one or multiple sources, and then produce a written material (Piolat et al., 2005). Cook and Mayer (1983) viewed that making notes and underlining important parts of studied materials would not only focus learners' attention but also promote knowledge construction and integration. Thus, there is no doubt that effective notetaking leads to better test performance (Baker \& Lombardi, 1985).

To study History effectively, students could make notes before, during, and after History class. Before class, students could preview the assigned topics, underline or highlight the important sentences, take notes, and try to relate them to existing knowledge or previous topics. Other than making notes from textbooks, students are also encouraged to do note-taking during History lessons. To do so, students should pay sedulous attention to their teachers and jot down 
important information or key ideas in short sentences. After class, students should rewrite their notes in a more organized order. Besides, students could come out their notes on flashcards. These portable flashcards take advantage of time; for instance, do a quick revision when waiting for a bus. This is not doubt that note-taking help students understand History lessons and retrieve them when necessary.

Having a last minute night-cramming is not a good idea. Instead, students are encouraged to do their revision regularly. Numerous studies showed that learners will substantially remember more and learn better if they restudy information in several occasions rather than in a single occasion only (Vlach et al., 2008; Wahlheim et al., 2011).

To summarize, students should have enough time to do revision for a durable learning in History. Revision should be done frequently.

\subsubsection{Elaboration-based Learning Techniques}

Elaboration-based learning techniques facilitate students' memory for simple facts to complex prose passages by adding meaning to the academic materials, constructions, or generations (Levin, 1988). Besides, elaboration techniques make students easier to understand and remember new information by creating connections to existing knowledge (Weinstein \& Underwood, 1985). In other words, elaboration learning strategies transfer existing knowledge which is stored in longterm memory into working memory and integrate the new information with existing knowledge (Weinstein \& Mayer 1986).

A study by Anderson and Bower (1973) provide a good example of how an elaboration technique leads to better memory (as cited in Anderson, 2015). Participants were asked to remember a sentence such as "The doctor hated the lawyer". The participants were then requested to either simply study the given sentence or have an elaborative processing on the sentence-e.g., "because of the malpractice suit". Beyond all doubt, participants who generated elaborations recalled more information, compared with their counterparts. This study implies that elaboration, a type of deeper information processing, encourages a better ability to recall than rote learning.

An example of applying elaboration in History could be illustrated through studying the formation of the Federation of Malaya. To do so, students could find out the meaningful connections and then interconnect them with their prior knowledge of Malayan Union, which came into existence before the Federation of Malaya. Students could ask a set of questions such as "Why did Malays oppose to the inauguration of the Malayan Union?", "Why did the British replace Malayan Union with the Federation of Malaya?", "What were the factors in the creation of a new federation?", "What are the differences between the Malayan Union and the Federation of Malaya?", and so forth. Students could also make a summary on the comparisons between them. By generating elaborations, students could reduce their confusion between the two federations and portrait a clear picture on how the history evolved in forming Malaysia.

In short, elaboration techniques enable students to have a deep processing on the new incoming information so that it could be integrated with prior knowledge. Thus, the new information could be stored in long-term memory.

\subsubsection{Mnemonics}

A student could try using mnemonic strategies to memorize historical facts. According to Gerrig (2013), mnemonics are strategies that relate new information with already stored information to aid subsequent retrieval of the novel information.

The first-letter technique, one of the popular mnemonic strategies, combines the first letter from each keyword into a word or sentence (Matlin, 2009). For instance, a student can create a mnemonic sentence such as "Cute $\underline{\text { Cat }} \underline{\text { Kisses }}$

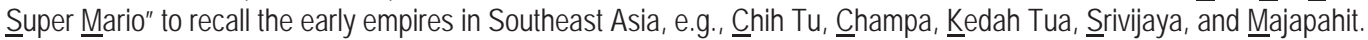

Another form of mnemonic strategies, narrative technique, as its name suggests, use stories to link a list of keywords (Matlin, 2009). In this case, a student should first find out the keywords from a textbook passage and then generate narrative stories to recall them. To remember the locations of agricultural societies, for example, a student might tell the story in this way- "When sightseeing in inland areas, I saw farmers cultivate fertile lands with crops along river valleys and lakeshores." From the story, the student could easily recall the locations, namely inland areas, fertile lands, river valleys, and lakeshores.

Besides, hierarchy is also an effective way to remember facts because information is organized in classes, starting from broader classes to more specific classes (Matlin, 2009). In one such experiment, Bower et al. (1969) found that participants with hierarchically organized word-lists had 2-3 times better recall rate than those with random word-lists. An example of the application of hierarchy is to differentiate primary and secondary sources. The hierarchy begins from a general class "Primary and Secondary Sources", and then the class is divided into "Primary Sources" and "Secondary Sources". Finally, both the classes would be further divided into "Definition" and "Examples". In this example, the developed hierarchy offers a clear snapshot on the differences between primary and secondary sources. 
Although mnemonics are helpful in recalling a long list of keywords, students are advised to do repetition to encode novel information in the memory system (McPherson, 2010). Besides, students also need to be creative in forming own mnemonics to ameliorate better memory.

\subsubsection{Comprehensive Approach}

As expected, every memory technique has a number of limitations. If any single above-mentioned study strategy seems ineffective to enhance memory, a spectrum of study strategies should be adopted. Thus, learners might have a comprehensive approach to obtain better learning results (Matlin, 2009). For example, Herrmann et al. (2002) claimed that college students who impose different study skills tend to gain better grades (as cited in Matlin, 2009).

The following parts will demonstrate examples of applying various memory strategies in learning History.

First example demonstrates using role playing as a memory enhancement strategy. Role playing, as viewed by Banikowski and Mehring (1999), is a form of active learning which enables students gaining knowledge from doing activities (or hand-on experience). In studying the Pangkor Treaty of 1874 (Perjanjian Pangkor 1874), for instance, a student can act as Raja Ismail and delivers the role with the emotion of anger, who got angry with Raja Abdullah because Raja Abdullah agreed to accept Sir James W.W. Birch as Perak's first British Resident and began the age of British colonization in Perak. After the role playing, the student could understand the given character more thoroughly.

Self-reference effect is also a practicable technique in learning History. Self-reference effect reflects the phenomenon in which one can have a better recall rate by relating novel information with personal information (Rogers, 1977). For example, research findings from Kesebir and Oishi (2010) showed that people tend to remember dates that are around their birthday. Thus, a student might benefit from this effect in remembering important dates which are nearer to his/her birthday.

Besides, numerous studies have confirmed the positive outcomes of using mind map in learning (Farrand et al., 2002; Mento et al., 1999). In learning History, a student could build a mind map by interconnecting relationships that emerge among the historical events. This technique provides a clear picture of how History evolves in a chronological order, thus making students easier to remember. Mind maps can be used to outline the logical flow of facts in a wide variety of History topics, including timeline of prehistory (Paleolithic, Mesolithic, and Bronze Age), the colonial history of Sarawak by the Brooke family, the establishment of the Malacca Sultanate by Parameswara, and so forth.

Apart from cognitive strategies, physical condition and diet appear to be pivotal in promoting better cognitive functioning. For examples, in a research conducted by Ellemberg and St-Louis-Deschênes (2010), the researchers found that children with regular exercise showed a significant improvement than those did not do so in completing cognitive tasks, whilst Shin et al. (2003) pointed out that insufficient sleep time is associated to poor learning outcomes. Besides, a longitudinal survey conducted by Vercambre et al. (2009) revealed that lower poultry, fish, and animal fats consumption is related to cognitive decline. Morris et al. (2005) also reported that fish intake would slow down the rate of cognitive decline. In short, these studies offer insights into the way of effective learning. Hence, students should pay attention to their lifestyle. Healthy students are better learners after all.

\section{Limitation, Recommendations, and Conclusion}

\subsection{Limitation}

The current research only focused on two participants and the participants did not constitute a representative sample of the target population. Hence, the findings could not be generalized to the Malaysian student population at large. However, this research provides some implications for those who have the exact same problem with the participants.

\subsection{Recommendations}

Teachers also play their roles to improve students' achievement in History. Teacher should avoid a full session of chalk and talk in teaching the subject matter. Instead, teachers should always look for ways to enhance students' learning outcomes. For examples, teachers should be creative in teaching, formulate acronyms to help students remember the main concepts, and engage students in group discussion activity which enables students to think critically.

To know the brain functioning mechanisms better, further studies could be conducted by using an electroencephalogram (EEG). EEG allows researchers to study the changes of one's brain before and after applying memory strategies. It might provide new empirical evidence and deeper understanding of how memory strategies 
facilitate learning.

\subsection{Conclusion}

History illustrates our past and makes us have a better understanding of ourselves. We know, indeed, those who do not learn from the past mistakes are doomed to repeat them. Additionally, History cultivates excessive patriotism. It is viewed as a significant tool to promote unity for a plural society-particularly Malaysia. Hence, History is a vital part of a national integration. Notwithstanding, some students are not interested in History. To fulfill the examination-oriented education, they study History by rote. Learning History in this way negatively influences the learning outcomes. Besides, the preconceived notion that learning History is a simple process of recalling facts should be cast aside. Numerous studies have provided vast memory strategies that can be used to facilitate learning. It is believed that students who use memory strategies appropriately - pay attention, do revisions regularly, generate elaborations, create mnemonics, or apply a comprehensive approach - are more likely to obtain better grades in History. Students can turn out to be better learners, who learn new information faster and more effectively, through memory strategies.

\section{References}

Anderson, J. R. (2015). Cognitive psychology and its implications, 8th ed. New York: Worth Publishers.

Atkinson, R. C., \& Shiffrin, R. M. (1968). Human memory: A proposed system and its control processes. In K. W. Spence \& J. T. Spence (Eds.), The psychology of learning and motivation, Vol. 2, (pp. 89-195). New York: Academic Press.

Azwan Ahmad, Abdul Ghani Abdullah, Mohammad Zohir Ahmad, \& Abd. Rahman Hj. Abdul Aziz. (2005). Kesan efikasi kendiri guru sejarah terhadap amalan pengajaran berbantukan teknologi maklumat dan komunikasi (ICT). Jurnal Penyelidikan Pendidikan, 7 , $15-24$.

Baker, L., \& Lombardi, B. R. (1985). Students' lecture notes and their relation to test performance. Teaching of Psychology, 12(1), 28-32. doi: 10.1207/s15328023top1201 9

Banikowski, A., \& Mehring, T. (1999). Strategies to enhance memory based on brain research. Focus on Exceptional Children, 32(2), 116.

Beyer, B. (2008). How to teach thinking skills in social studies and history. Social Studies, 99(5), 196-201. doi:10.3200/TSSS.99.5.196201

Bower, G. H., Clark, M. C., Lesgold, A. M., \& Winzenz, D. (1969). Hierarchical retrieval schemes in recall of categorized word lists. Journal of Verbal Learning and Verbal Behavior, 8(3), 323-343.

Brophy, J. E., \& VanSledright, B. A. (1997). Teaching and learning History in elementary school. New York: Teachers College Press.

Butterfield, E. C., Wambold, C., \& Belmont, J. M. (1973). On the theory and practice of improving short-term memory. American Journal of Mental Deficiency, 77(5), 654-669.

Carretti, B., Borella, E., \& De Beni, R. (2007). Does strategic memory training improve the working memory performance of younger and older adults?. Experimental Psychology, 54(4), 311-320.

Carter, K., \& Seifert, C. M. (2013). Learn psychology. Burlington, MA: Jones \& Bartlett Learning.

Cavallini, E., Pagnin, A., \& Vecchi, T. (2003). Aging and everyday memory: The beneficial effect of memory training. Archives of Gerontology and Geriatrics, 37(3), 241-257. doi:10.1016/S0167-4943(03)00063-3

Cook, L. K., \& Mayer, R. E. (1983). Reading strategies training for meaningful learning from prose. In M. Pressley and J. R. Levin (Eds.), Cognitive strategy research: Educational applications, (pp.87-131). New York: Springer-Verlag.

Creswell, J. W. (2012). Educational research: Planning, conducting, and evaluating quantitative and qualitative research (4th ed.). Upper Saddle River, NJ: Pearson.

Dudukovic, N. M., DuBrow, S., \& Wagner, A. D. (2009). Attention during memory retrieval enhances future remembering. Memory \& Cognition, 37(7), 953-961. doi:10.3758/MC.37.7.953

Ellemberg, D., \& St-Louis-Deschênes, M. (2010). The effect of acute physical exercise on cognitive function during development. Psychology of Sport and Exercise, 11(2), 122-126. doi:10.1016/j.psychsport.2009.09.006

Farrand, P., Hussain, F., \& Hennessy, E. (2002). The efficacy of the 'mind map' study technique. Medical Education, 36(5), 426-431. doi:10.1046/j.1365-2923.2002.01205.x

Fowler, R. L., \& Barker, A. S. (1974). Effectiveness of highlighting for retention of text material. Journal of Applied Psychology, 59(3), 358-364. doi:10.1037/h0036750.

Fylan, F. (2005). Semi-structured interviewing. In J. Miles \& P. Gilbert (Eds.), A handbook of research methods for clinical and health psychology (pp. 65-77). New York: Oxford University Press.

Gerrig, R. J. (2013). Psychology and life, 20th ed. Upper Saddle River, NJ: Pearson.

Goldstein, E. B. (2011). Cognitive psychology: Connecting mind, research, and everyday experience (3rd ed.). Belmont, CA: Cengage Learning.

Gültekin, F., \& Berk, N. A. (2011). The topics students have difficulty in understanding and learning in history course. Procedia Social and Behavioral Sciences, 15, 2803-2807. doi:10.1016/j.sbspro.2011.04.192 
Huitt, W. (2003). The information processing approach to cognition. Educational Psychology Interactive. Valdosta, GA: Valdosta State University. Retrieved 26 January, 2015 from, http://www.edpsycinteractive.org/topics/cognition/infoproc.html

Hygge, S., Evans, G. W., \& Bullinger, M. (2002). A prospective study of some effects of aircraft noise on cognitive performance in schoolchildren. Psychological Science, 13(5), 469-474. doi:10.1111/1467-9280.00483

Hygge, S., \& Knez, I. (2001). Effects of noise, heat and indoor lighting on cognitive performance and self-reported affect. Journal of Environmental Psychology, 21(3), 291-299. doi:10.1006/jevp.2001.0222

Jenkins, T. (2002, 27-29 August). On the difficulty of learning to program. In Proceedings of the 3rd annual LTSN_ICS conference (pp. 53-58), Loughborough University.

Kesebir, S., \& Oishi, S. (2010). A spontaneous self-reference effect in memory: Why some birthdays are harder to remember than others. Psychological Science, 21(10), 1525-1531. doi:10.1177/0956797610383436

Levin, J. R. (1988). Elaboration-based learning strategies: Powerful theory=powerful application. Contemporary Educational Psychology, 13(3), 191-205. doi:10.1016/0361-476X(88)90020-3

Lieberman, D. A. (2012). Human learning and memory. New York: Cambridge University Press.

Loomes, C., Rasmussen, C., Pei, J., Manji, S., \& Andrew, G. (2008). The effect of rehearsal training on working memory span of children with fetal alcohol spectrum disorder. Research in Developmental Disabilities, 29(2), 113-124. doi:10.1016/j.ridd.2007.01.001

Matlin, M. W. (2009). Cognitive psychology, 7th ed. Asia: John Wiley \& Sons (Asia) Pte Ltd.

McPherson, F. (2010). Mnemonics for study. Wellington, New Zealand: Wayz Press.

Mento, A. J., Martinelli, P., \& Jones, R. M. (1999). Mind mapping in executive education: Applications and outcomes. Journal of Management Development, 18(4), 390-416.

Miller, G. A. (1956). The magical number seven, plus or minus two: Some limits on our capacity for processing information. Psychological review, 63(2), 81.

Mohamad Johdi Salleh, Baharom Mohamad, \& Abdul Said Ambotang. (2013). The significant of History curriculum in the development of active citizen: A critical analysis of the ICSS History, Malaysia. International Journal of Scientific and Research Publications, 3(9), 1-8.

Mohs, R. C., Ashman, T. A., Jantzen, K., Albert, M., Brandt, J., Gordon, B., Rasmusson, X., Grossman, M., Jacobs, D., \& Stern, Y. (1998) A study of the efficacy of a comprehensive memory enhancement program in healthy elderly persons. Psychiatry Research, 77: 183-195. doi:10.1016/S0165-1781(98)00003-1

Morris, M. C., Evans, D. A., Tangney, C. C., Bienias, J. L., \& Wilson, R. S. (2005). Fish consumption and cognitive decline with age in a large community study. Archives of Neurology, 62(12), 1849-1853. doi:10.1001/archneur.62.12.noc50161.

Piolat, A., Olive, T., \& Kellogg, R. T. (2005). Cognitive effort during note taking. Applied Cognitive Psychology, 19(3), $291-312$.

Rapp, S., Brenes, G., \& Marsh, A. P. (2002). Memory enhancement training for older adults with mild cognitive impairment: A preliminary study. Aging \& Mental Health, 6(1), 5-11. doi:10.1080/13607860120101077

Reisman, A., \& Wineburg, S. (2008). Teaching the skill of contextualizing in history. The Social Studies, 99(5), $202-207$. doi:10.3200/TSSS.99.5.202-207

Rickards J. P., August G. J. (1975). Generative underlining strategies in prose recall. Journal of Educational Psychology, 67, 860-865. doi:10.1037/0022-0663.67.6.860

Rogers, T. B., Kuiper, N. A., \& Kirker, W. S. Self-reference and the encoding of personal information. Journal of Personality and Social Psychology, 1977, 35(9), 677-688.

Schwartz, B. L., Son, L. K., Kornell, N., \& Finn, B. (2011). Four principles of memory improvement: A guide to improving learning efficiency. The International Journal of Creativity and Problem Solving, 21(1), 7-15.

Shin, C., Kim, J., Lee, S., Ahn, Y., \& Joo, S. (2003). Sleep habits, excessive daytime sleepiness and school performance in high school students. Psychiatry and Clinical Neurosciences, 57(4), 451-453. doi:10.1046/j.1440-1819.2003.01146.x

Smith, E. E., \& Kosslyn, S. M. (2007). Cognitive psychology: Mind and brain. Upper Saddle River, N.J: Pearson/Prentice Hall.

Sternberg, R. J. (2009). Cognitive psychology (5th ed.). Belmont, CA: Cengage Learning.

Teddlie, C., \& Yu, F. (2007). Mixed methods sampling: A typology with examples. Journal of Mixed Mmethods Research, 1(1), 77-100. doi:10.1177/2345678906292430

Tongco, M. D. C. (2007). Purposive sampling as a tool for informant selection. Ethnobotany Research and Applications, 5, 147-158.

Tuckman, B. W. (2003). The effect of learning and motivation strategies training on college students' achievement. Journal of College Student Development, 4, 430-437. doi:10.1353/csd.2003.0034

Vercambre, M. N., Boutron-Ruault, M. C., Ritchie, K., Clavel-Chapelon, F., \& Berr, C. (2009). Long-term association of food and nutrient intakes with cognitive and functional decline: A 13-year follow-up study of elderly French women. British Journal of Nutrition, 102(03), 419-427. doi:10.1017/S0007114508201959

Vlach, H. A., Sandhofer, C. M., \& Kornell, N. (2008). The spacing effect in children's memory and category induction. Cognition, 109(1), 163-167. doi:10.1016/j.cognition.2008.07.013

Wahlheim, C. N., Dunlosky, J., \& Jacoby, L. L. (2011). Spacing enhances the learning of natural concepts: An investigation of mechanisms, metacognition, and aging. Memory \& Cognition, 39(5), 750-763. doi:10.3758/s13421-010-0063-y

Ward, A. (2004). Attention: A neuropsychological approach. New York: Psychology Press.

Weinstein, C. E., \& Mayer, R. E. (1986). The teaching of learning strategies. In M. C. Wittrock (Ed.), The handbook of research on teaching (3rd ed., pp. 315-327). New York: Macmillan.

Weinstein, C. E., \& Underwood, V. L. (1985). Learning strategies: The how of learning. In J. W. Segal, S. F. Chipman, \& R. Glaser 
(Eds.), Thinking and learning skills, Vol. 1, (pp. 241 -258). Hillsdale, NJ: Erlhaum.

Wood, S. E., Wood, E. G, \& Boyd, D. (2011). The world of psychology (11st ed.). Boston, MA: Pearson.

Yin, R. K. (2009). Case Study Research: Design and Methods. California: SAGE Publications. 